\title{
Differentiating Suicide Attempters from Suicide Ideators: A Critical Frontier for Suicidology Research
}

\author{
E. David Klonsky, PhD, and Alexis M. May, MA
}

\begin{abstract}
Most individuals who consider suicide do not make suicide attempts. It is therefore critical to identify which suicide ideators are at greatest risk of acting on their thoughts. However, few seminal theories of suicide address which ideators go on to make attempts. In addition, perhaps surprisingly, most oft-cited risk factors for suicide - such as psychiatric disorders, depression, hopelessness, and even impulsivity - distinguish poorly between those who attempt suicide and those who only consider suicide. This special section of Suicide and LifeThreatening Behavior serves to highlight this knowledge gap and provide new data on differences (and similarities) between suicide attempters and suicide ideators.
\end{abstract}

Suicide is a leading cause of death in the United States and worldwide (Centers for Disease Control and Prevention, 2011; World Health Organization, 2011). Unfortunately, despite increased prevention efforts, suicide rates over the past several decades appear to be increasing (World Health Organization, 2011). To reduce suicide deaths, the field must meaningfully improve its understanding of suicide.

One reason for limited progress in suicide prevention may be a lack of knowledge about the transition from suicidal thoughts to suicidal actions. Most people who consider suicide do not go on to make a suicide attempt. For example, in a large population-based study, only $7.4 \%$ of those with baseline suicidal ideation reported a suicide attempt over the subsequent 2 years

E. David Klonsky and Alexis M. May, Department of Psychology, University of British Columbia, Vancouver, BC, Canada.

Address correspondence to David Klonsky, Department of Psychology, University of British Columbia, Vancouver, BC, Canada; E-mail: EDKlonsky@psych.ubc.ca (ten Have et al., 2009). Overall, lifetime rates of suicide ideation are many times higher than lifetime rates of attempts (Fergusson, Beautrais, \& Horwood, 2003; Kessler, Borges, \& Walters, 1999). It is therefore critical to understand differences between suicide attempters and suicide ideators, ${ }^{1}$ and to identify which ideators are at greatest risk of suicide attempts. This information could greatly improve risk assessment and theoretical models of suicide.

However, a close examination of the suicide literature reveals a key knowledge gap. Specifically, oft-cited risk factors for suicide are, in actuality, risk factors for suicide ideation, and not for progression from suicide ideation to attempts.

Consider data from the National Comorbidity Survey (Kessler et al., 1999). In this large epidemiological study, odds ratios were quite high for distinguishing suicide ideators from those who have never been suicidal. For example, odds ratios were 9.5

${ }^{1}$ For the purposes of this article, the term ideators is used to indicate individuals who have considered but not attempted suicide. 
for major depression, 10.7 for any mood disorder, 5.1 for posttraumatic stress disorder, and 14.3 for the presence of three or more clinical disorders, meaning that individuals with these conditions were much more likely to be ideators than individuals without those conditions. In contrast, when it came to distinguishing attempters from ideators, odds ratios for these risk factors were very low, ranging from a high of 2.3 (indicating minimal association with attempts) to a low of 1.0 (indicating no relationship whatsoever). This pattern led Kessler et al. (p. 617) to conclude: "All significant risk factors ... were more strongly related to ideation than to progression from ideation to a plan or an attempt." Notably, this general pattern reported by Kessler et al. was subsequently found in other large-scale studies as well, including an international epidemiological study examining suicidality across 21 countries (Nock, Borges, \& Ono, 2012), and an epidemiological study of adolescents (Nock et al., 2013).

Because the studies described earlier focus on psychiatric disorders, we want to be clear that this same pattern applies to other risk factors as well. For example, hopelessness has long been emphasized as an important suicide risk factor (Beck, Steer, Kovacs, \& Garrison, 1985). However, careful examination of the literature indicates that, while elevated among suicide ideators relative to nonsuicidal controls, hopelessness fails to discriminate between suicide ideators and attempters. For example, in a study of 102 psychiatric patients with bipolar disorder, hopelessness was higher among both suicide ideators and attempters relative to healthy controls, but equivalent between suicide ideators and attempters (Acosta et al., 2012). The same finding - that hopelessness is no higher among attempters than ideators-has been observed in psychiatric patients with depression (Vuorilehto, Melartin, \& Isometsa, 2006) and youth receiving psychiatric care (Nock \& Kazdin, 2002; Rudd, Joiner, \& Rajab, 1996). The pattern even holds when comparing hopelessness between "severe attempters" and suicide ideators (Apter, Horesh, Gothelf, Graffi, \& Lepkifker, 2001).

It is important to devote special attention to the role of impulsivity. Not only is impulsivity often cited as a suicide risk factor, but impulsivity has been singled out as key for facilitating the transition from suicidal thoughts to attempts. For example, individuals high on impulsivity have been described as being "more likely to act on suicidal feelings" (Mann, Waternaux, Haas, \& Malone, 1999, p. 186). Similarly, impulsivity has been suggested as "a more significant indicator of suicide attempt than the presence of a specific suicide plan" (Rudd \& Bryan, 2006, p. 195). An implication of these theoretical perspectives is that impulsivity should be higher in suicide attempters than ideators.

Notably, empirical findings do not support the notion that impulsivity is higher in attempters than ideators. In a large military sample, impulsivity was higher among attempters and ideators compared with nonsuicidal individuals, but equivalent between attempters and ideators (Klonsky \& May, 2010). Similar findings were observed when a multidimensional model of impulsivity (i.e., the UPPS model; Whiteside, Lynam, Miller, \& Reynolds, 2005) was utilized; specifically, attempters and ideators were equivalent on the impulsivity-related traits of urgency (acting rashly in response to negative emotion), perseverance (ability to persist in tasks despite fatigue or boredom), and sensation seeking (preference for excitement and stimulation) (Klonsky \& May, 2010). Interestingly, attempters did report slightly more problems with premeditation (ability to think through consequences before acting) than ideators, but this effect was very small (Cohen's $d=.27$ ). Further problematic conceptualizations of impulsivity in suicide have been noted by others (Witte et al., 2008; Wyder \& DeLeo, 2007), but are beyond the scope of the present article. In short, like hopelessness and myriad psychiatric disorders, impulsivity provides little, if any, information about 
differences between suicide attempters and suicide ideators.

It may come as a surprise to some that so many oft-cited risk factors for suicide are in fact predictors of suicide ideation, not predictors of the progression from ideation to attempt. However, this knowledge gap may be traced to the theoretical literature. Historically, theories of suicide have conflated the question of why people feel suicidal with the question of why people act on suicidal thoughts. For example, major theories have emphasized the roles of psychache (Shneidman, 1993), escape (Baumeister, 1990), and social isolation (Durkheim, 1951) without specifying whether these factors explain suicide ideation, attempts, or both.

The past decade has seen a shift in the nature of suicide theories. In 2005, Thomas Joiner introduced his interpersonal theory of suicide (Joiner, 2005). This theory is the first to utilize a desire-capability framework, in which different explanations are offered for suicidal desire and for the capability to act on suicidal desire. The interpersonal theory states that perceived burdensomeness and low belongingness combine to create suicidal desire, whereas the capability to act on desire is acquired over time through exposure to painful and provocative events (Van Orden et al., 2010). Although the theory is relatively new, there is emerging evidence that suicide capability indeed is elevated among suicide attempters relative to suicide ideators (Smith, Cukrowicz, Poindexter, Hobson, \& Cohen, 2010; Van Orden, Witte, Gordon, Bender, \& Joiner, 2008). In addition, it is encouraging that other recent theories also offer different explanations for suicide ideation versus suicide attempts. For example, Rory O'Connor's motivationalvolitional theory of suicidal behavior (O'Connor, 2011) agrees with Joiner that the propensity to act on suicidal thoughts is increased by acquired capability, but emphasizes additional factors, such as dispositional pain sensitivity and physical access to lethal means, that may further increase the likelihood of suicide attempts.
It is our opinion that an ideationto-action framework should guide all suicide research and theory (ideation-to-action term suggested by $\mathrm{N}$. Neufeld, personal communication, September 6, 2013). That is, predictors and explanations for suicide should be classified as to whether they address (a) risk of suicide ideation, (b) risk of suicide attempts among those with ideation, or (c) both. For example, as discussed earlier, hopelessness and most psychiatric disorders appear to be best characterized as predictors of suicide ideation (Apter et al., 2001; Kessler et al., 1999; Rudd et al., 1996). In contrast, reduced pain sensitivity and fearlessness appear to specifically characterize suicide attempters, but not ideators (Smith et al., 2010). Other risk factors, such as nonsuicidal self-injury, appear to confer risk of both suicide ideation and attempts (Klonsky, May, \& Glenn, 2013). Moving forward, theory and research guided by an ideation-to-action framework can greatly improve models of suicide risk as well as efforts to understand and prevent suicide.

The aim of this special section, entitled "Differentiating Suicide Attempters from Suicide Ideators," is not only to highlight the need to better understand progression from ideation to attempts, but to provide new data. In this section, we are fortunate to have contributions from leading suicide researchers on the topic of differentiating suicide attempters from ideators. Taliaferro and Muehlenkamp (2013; this issue), consistent with previous work described in this article, found that hopelessness and depression were elevated among adolescent ideators compared with nonsuicidal adolescents, but equivalent between ideators and attempters; in contrast, a self-injury history was more characteristic of attempters than ideators. O'Brien et al. (2013; this issue) examined adolescent psychiatric inpatients and found that depression but not alcohol use differentiated suicide ideators from nonsuicidal individuals, whereas alcohol use but not depression was elevated in attemp- 
ters compared with ideators. Stack (2013; this issue) identified violence as a factor that, in different forms, may predict both suicide ideation and progression from ideation to attempts. Finally, Pompili et al. (2013; this issue) investigated a geriatric sample with mood disorders and found that attempters were much more likely to report low social support compared with ideators. At the same time, highlighting the need for additional work, Pompili et al. noted that

\section{REFERENCES}

Acosta, F. J., Vega, D., Torralba, L., Navarro, S., Ramallo-Farina, Y., Fiuza, D., ET AL. (2012). Hopelessness and suicidal risk in bipolar disorder: A study in clinically nonsyndromal patients. Comprehensive Psychiatry, 53, 11031109.

Apter, A., Horesh, N., Gothelf, D., Graffi, H., \& LePKifKer, E. (2001). Relationship between self-disclosure and serious suicidal behavior. Comprehensive Psychiatry, 42, 70-75. doi:10.1053/comp.2001.19748.

Baumeister, R. F. (1990). Suicide as escape from self. Psychological Review, 97, 90-113.

Beck, A. T., Steer, R. A., Kovacs, M., \& Garrison, B. (1985). Hopelessness and eventual suicide: A 10-year prospective study of patients hospitalized with suicidal ideation. American Fournal of Psychiatry, 142, 559-563.

Bryan, C. J., \& Rudd, M. D. (2006). Advances in the assessment of suicide risk. Fournal of Clinical Psychology: In Session, 62, 185-200.

Centers for Disease Control and Prevention. (2011). Web-based Injury Statistics Query and Reporting System (WISQARS) [Online]. National Center for Injury Prevention and Control, CDC (producer). Available from URL: http://www. cdc.gov/injury/wisqars

Durkheim, E. (1951). Suicide: A study in sociology. New York: Free Press.

Fergusson, D. M., Beautrais, A. L., \& Horwood, L. J. (2003). Vulnerability and resiliency to suicidal behaviours in young people. Psychological Medicine, 33, 61-73.

ten Have, M., de Graaf, R., van DorsSelaer, S., Verdurmen, J., Van 'T Land, H., VOlleberGH, W., ET AL. (2009). Incidence and course of suicidal ideation and suicide attempts in the general population. Canadian Fournal of Psychiatry, 54, 824-833.

JoIner, T. E. (2005). Why people die by suicide. Cambridge: Harvard University Press. attempters and ideators were similar on "several variables assumed to be risk factors for suicide behavior."

When it comes to suicide, the stakes are high, and it is important to get the science right. We hope this special section has succeeded in highlighting a key knowledge gap, providing new and useful data, and stimulating a new wave of theory and research that will meaningfully improve suicide science and prevention.

Kessler, R. C., Borges, G., \& Walters, E. E. (1999). Prevalence of and risk factors for lifetime suicide attempts in the national comorbidity survey. Archives of General Psychiatry, 56, 617-626.

KLONSKY, E. D., \& MAY, A. M. (2010). Rethinking impulsivity in suicide. Suicide and Life-Threatening Behavior, 40, 612-619.

Klonsky, E. D., May, A. M., \& Glenn, C. R. (2013). The relationship between nonsuicidal self-injury and attempted suicide: Converging evidence from four samples. Fournal of Abnormal Psychology, 122, 231-237.

Mann, J. J., Waternaux, C., Haas, G. L., \& Malone, K. M. (1999). Toward a clinical model of suicidal behavior in psychiatric patients. American Fournal of Psychiatry, 156, 181-189.

Nock, M. K., Borges, G., \& ONO, Y. (Eds.) (2012). Suicide: Global perspective from the WHO world mental health surveys (1st ed.). Cambridge, UK: Cambridge University Press.

Nock, M. K., Greif Green, J., Hwang, I., Mclaughlin, K. A., Sampson, N. A., \& ZASlavsky, A. M., ET AL. (2013). Prevalence, correlates, and treatment of lifetime suicidal behavior among adolescents. $7 A M A, 70,300-310$.

Nock, M. K., \& Kazdin, A. E. (2002). Examination of affective, cognitive, and behavioral factors and suicide-related outcomes in children and young adolescents. Fournal of Clinical Child and Abnormal Psychology, 31, 48-58.

O’Brien, K. H. M., Becker, S. J., Spirito, A., Simon, V., \& Prinstien, M. (2013). Differentiating adolescent suicide attempters from ideators: Examining the interaction between depression severity and alcohol use. Suicide and Life-Threatening Behavior, doi: 10.1111/sltb. 12050. [Epub ahead of print]

O'Connor, R. C. (2011). Towards an integrated motivational-volitional model of suicidal behaviour. In R. C. O'Connor, S. Platt \& 
J. Gordon (Eds.), International Handbook of Suicide Prevention: Research, Policy and Practice. Chicester, UK: John Wiley.

Pompili, M., Innamorati, M., Di VitTorio, C., Sher, L., Girardi, P., \& Amore, M. (2013). Sociodemographic and clinical differences between suicide ideators and attempters: A study of mood disordered patients 50 years and older. Suicide and Life-Threatening Behavior, doi: 10.1111/sltb.12051. [Epub ahead of print]

RudD, M. D., JoIner, T., \& RAJAB, M. H. (1996). Relationships among suicide ideators, attempters, and multiple attempters in a youngadult sample. Fournal of Abnormal Psychology, 105, $541-550$.

Shneidman, E. S. (1993). Suicide as psychache: A clinical approach to self-destructive behavior. Northfield, NJ: Jason Aronson.

Smith, P. N., Cukrowicz, K. C., Poindexter, E. K., Hobson, V., \& Cohen, L. M. (2010). The acquired capability for suicide: A comparison of suicide attempters, suicide ideators, and non-suicidal controls. Depression and Anxiety, 27, 871-877.

STACK, S. (2013).Differentiating suicide ideators from attempters: Violence, a research note. Suicide and Life-Threatening Behavior, doi: 10.1111/sltb.12054. [Epub ahead of print]

Taliaferro, L., \& Muehlenkamp, J. J. (2013). Risk and protective factors that distinguish adolescents who attempt suicide from those who only consider suicide in the past year. Suicide and Life-Threatening Behavior, doi: 10.1111/sltb.12046. [Epub ahead of print]

Van Orden, K. A., Witte, T. K., Cukrowicz, K. C., Braithwaite, S. R., Selby, E. A., \& JoIner, T. E. (2010). The interpersonal theory of suicide. Psychological Review, 117, 575600 .

Van Orden, K. A., Witte, T. K., Gordon, K. H., Bender, T. W., \& Joiner, T. E. (2008). Suicidal desire and the capability for suicide: Test of the interpersonal psychological theory of suicidal behavior among adults. Fournal of Consulting and Clinical Psychology, 76, 72-83.

Vuorilehto, M. S., Melartin, T. K., \& Isometsa, E. T. (2006). Suicidal behaviour among primary-care patients with depressive disorders. Psychological Medicine, 36, 203-210. doi:10.1017/S0033291705006550.

Whiteside, S. P., Lynam, D. R., Miller, J. D., \& Reynolds, S. K. (2005). Validation of the UPPS impulsive behavior scale: A four-factor model of impulsivity. European Fournal of Personality, 19, 559-574.

Witte, T. K., Merrill, K. A., Stellrecht, N. E., Bernert, R. A., Hollar, D. L., Schatschneider, C., ET AL. (2008). "Impulsive" youth suicide attempters are not necessarily all that impulsive. Fournal of Affective Disorders, 107, 107-116.

World Health Organization. (2011). Figures and facts about suicide. Geneva, Switzerland: Author. Retrieved October 12, 2013, from http://www.who.int/mental_health/prevention/ suicide/country_reports/en/

Wyder, M., \& DE LeO, D. (2007). Behind impulsive suicide attempts: Indications from a community study. Fournal of Affective Disorders, 104, 167-173.

Manuscript Received: October 14, 2013

Revision Accepted: October 14, 2013 